\title{
Dominant transmission of Sprengel's shoulder and cleft palate
}

\author{
SHIRLEY V HODGSON AND DANIEL C CHIU
}

From the Paediatric Research Unit, Prince Philip Research Laboratories, Guy's Hospital Medical School, London SEI 9RT

SUMMARY We present a family showing apparently autosomal dominant transmission of Sprengel's shoulder with cleft palate. Some, but not all, of the kindred showed features of the Klippel-Feil syndrome. The association between these abnormalities is discussed.

The isolated abnormality of cleft palate is considered to be inherited in a multifactorial manner, although when associated with lip pits, cleft palate is inherited as a Mendelian dominant condition (Van der Woude Received for publication 16 July 1980 syndrome). ${ }^{1}$ Sprengel's shoulder (congenital raising of the scapula) usually occurs as a sporadic event, but there are six cases of isolated Sprengel's shoulder showing Mendelian inheritance. ${ }^{2}$ We report a family in which these two abnormalities are associated and

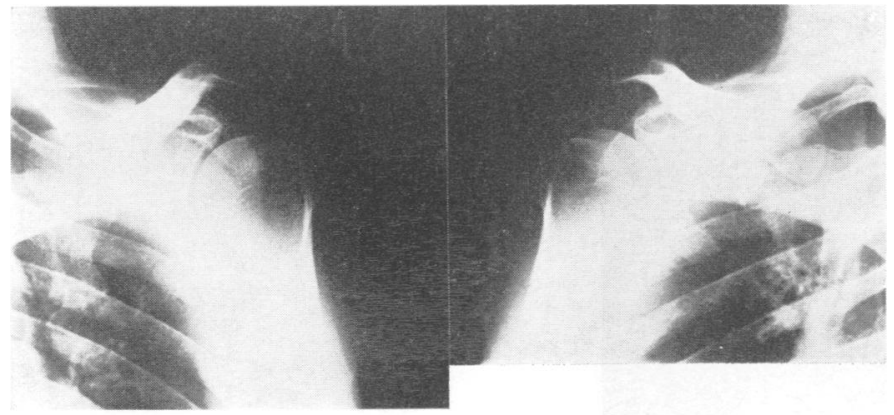

(a)

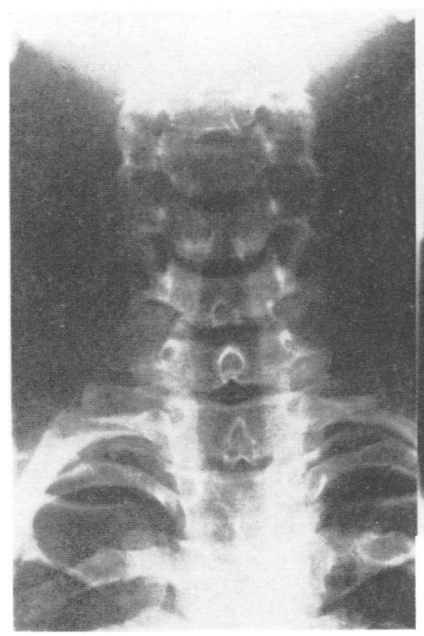

(c) (b)

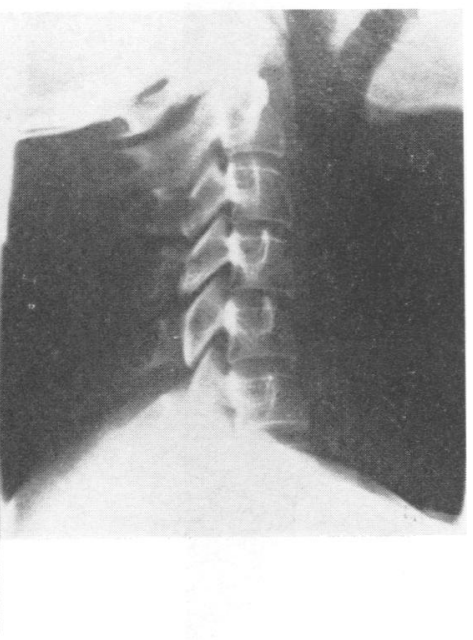

(d)
FIG $1 X$-rays of cervical spine and shoulders of the proband. 


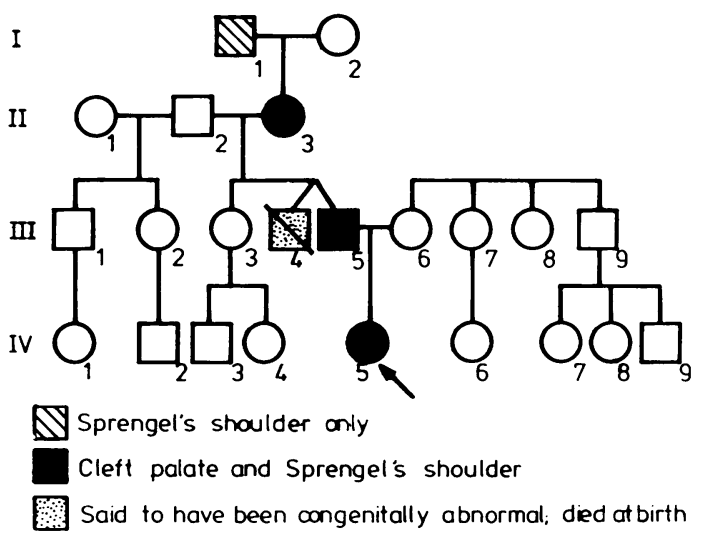

FIG 2 Pedigree of family. inherited together in a dominant manner. This has not to our knowledge been described before. One $\overrightarrow{\bar{N}}$ member of the family had a Klippel-Feil anomaly of the neck, which has been reported to be associated with each of these other anomalies separately.

\section{Case reports}

A 26-year-old woman attended our clinic for genetic advice because she had a cleft palate. On examination she had a repaired congenital cleft palate without $\vec{\omega}$

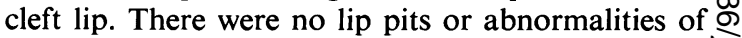
the teeth and the palate was not arched. She also $\overline{3}$ had bilateral Sprengel's shoulder with large wide scapulae rotated medially and placed high on the $\vec{\rho}$ thoracic cage. She could not raise her arms above it the horizontal, and there was some limitation of $\mathcal{E}$ neck movement, but the neck was not short. There 0 were no other orthopaedic abnormalities and her hearing and intelligence were normal. $X$-ray of the cervical spine was entirely normal (fig 1 ).

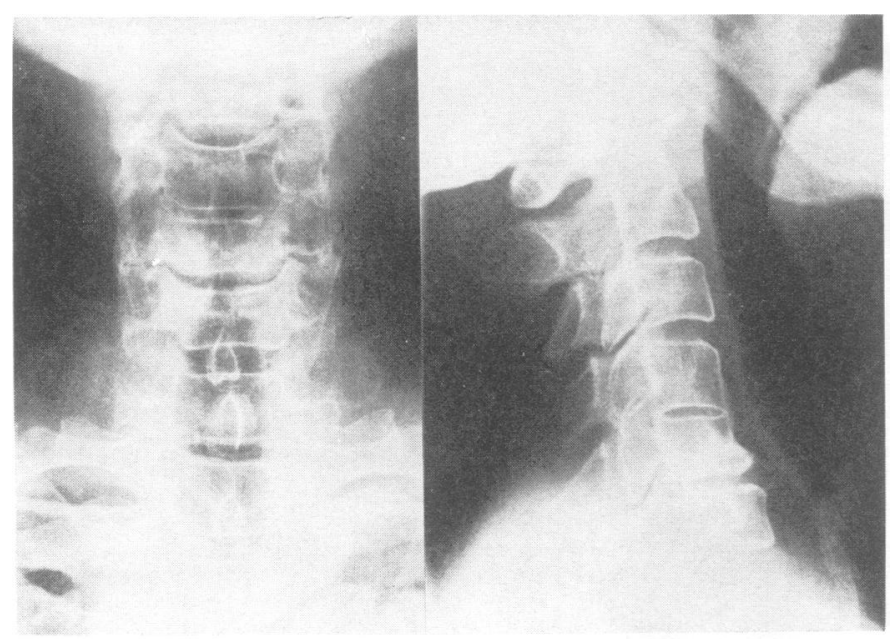

(a)

(b)

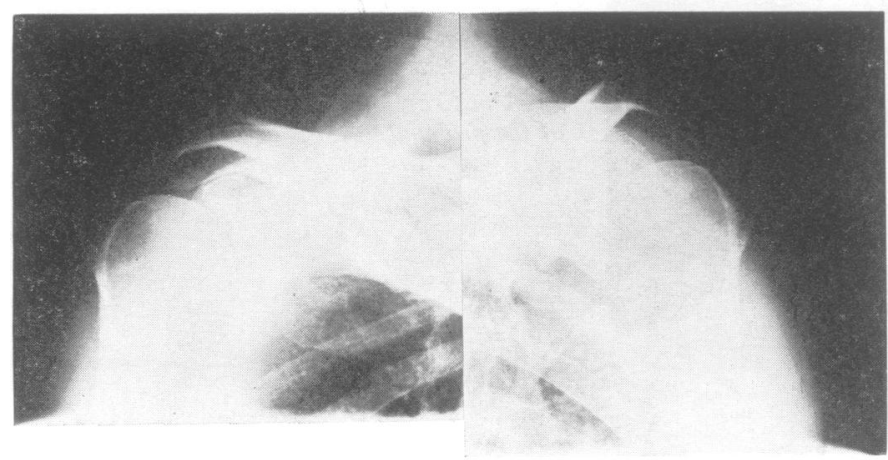

FIG $3 X$-rays of cervical spine and shoulders of the proband's father. (c)

(d) 
Both her father and paternal grandmother had cleft palate and bilateral Sprengel's shoulder, and her affected grandmother's father had bilateral Sprengel's shoulder but no cleft palate (fig 2). The father of the proband was a twin, but the other twin had died at birth and was said to have been deformed.

The father was examined. He had a cleft palate and bilateral Sprengel's shoulder, more pronounced on the right than on the left. He also had a short neck with limitation of movement, particularly rotation. The arm movements were also restricted. The palate was not arched and the palatal cleft had been repaired. His lips were normal and he had normal dentition.

$X$-ray of his cervical spine showed a fusion of the arches and bodies of the fourth and fifth vertebrae. The other vertebrae showed spondylotic change at $\mathrm{C} 5 / 6$ and there was degenerative disease of the posterior intervertebral joints at C5/6 (fig 3).

\section{Discussion}

There are two published reports which present firm evidence of Mendelian inheritance of Sprengel's shoulder. ${ }^{2} 3$ In both cases this was dominantly inherited through several generations. Four other families $^{2}$ have been reported with small pedigrees which present possible evidence of Mendelian inheritance, but the pedigrees are too limited for certainty. In none of these pedigrees was cleft palate reported.

Sprengel's shoulder deformity is associated with congenital defects of the cervical and thoracic vertebrae and ribs in about $50 \%$ of cases. Those associated with cervical vertebral anomalies merge into the Klippel-Feil syndrome, characterised by fusion of two or more cervical vertebrae, giving the clinical triad of short neck, low posterior hairline, and limitation of head and neck movements. The frequency of Sprengel's shoulder in Klippel-Feil syndrome has been given as $30 \%{ }^{4}$ Klippel-Feil syndrome is probably of heterogeneous aetiology and is usually sporadic, although familial cases with possible dominant inheritance have been reported. ${ }^{5}$
Cleft palate has been described in 5 to $20 \%$ of cases of Klippel-Feil syndrome. ${ }^{46}$ One explanation is that there is a developmental link between cervical fusion and cleft palate, with vertebral fusion causing compression of the mandible against the chest, forcing the tongue between the palatal shelves and preventing their closure in the midline. ${ }^{67}$ With the family reported here, however, Klippel-Feil syndrome was absent in the proband with cleft palate although present in her father, indicating that this mechanical explanation cannot be invoked in this kindred. The association of these anomalies within one kindred with autosomal dominant inheritance of cleft palate and Sprengel's shoulder, each of which has separately been reported with the Klippel-Feil syndrome, suggests that these three anomalies are very closely linked.

We wish to thank Dr A C Berry for her encouragement and advice in preparing this report.

\section{References}

1 Van der Woude A. Fistula labii inferioris congenita and its association with cleft lip and palate. Am J Hum Genet $1954 ; 6: 244-6$.

2 Wilson MG, Mikity VG, Shinno NW. Dominant inheritance of Sprengel's deformity. J Pediatr 1971;79:818-21.

3 Gottesleben A. Uber den doppelseitigen und einseitigen Schulterblatthochstand. Arch Klin Chir 1927;144:723-31.

4 Gorlin RJ, Pindberg JJ, Cohen MM. Syndromes of the head and neck. 2nd ed. New York, London: McGrawHill, 1976.

5 Gunderson CH, Greenspan RH, Glaser GH, Lubs HA. The Klippel-Feil syndrome: genetic and clinical reevaluation of cervical fusion. Medicine (Baltimore) 1967; 46:491-512.

6 Sommerfeld RM, Schweiger JW. Cleft palate associated with Klippel-Feil syndrome. Report of a case. Oral Surg 1969;27:737-9.

7 Ross RB, Lindsay WK. The cervical vertebrae as a factor in the etiology of cleft palate. Cleft Palate J 1965;2:27381 .

Requests for reprints to Dr S V Hodgson, Paediatric Research Unit, Prince Philip Research Laboratories, Guy's Hospital Medical School, London SE1 9RT. 